\title{
Effect of Manganese Segregation on Fine-grained Ferrite Structure in Low-carbon Steel Slabs
}

\author{
Teruo YAMASHITA, Shiro TORIZUKA ${ }^{11}$ and Kotobu NAGAI) \\ Hiroshima R \& D Center, Mitsubishi Heavy Industries., LTD., Kan-on-shinmachi, Hiroshima 733-8553 Japan. \\ 1) National Institute for Materials Science, Sengen, Tsukuba 305-0047 Japan.
}

(Received on March 18, 2003; accepted in final form on June 22, 2003)

\begin{abstract}
Using a $100 \mathrm{~mm}$ thick continuously cast slab with a chemical composition of $0.10 \mathrm{C}-0.16 \mathrm{Si}-0.58 \mathrm{Mn}-$ $0.01 \mathrm{P}-0.003 \mathrm{~S}$ (mass\%), we have clarified the effect of the manganese segregation on the transformed ferrite structure when the slab was reheated to make austenite grains equi-axed and smaller and followed by the Grain Refinement Process (GRP) of heavy compression and subsequent controlled cooling. Samples from which the $\mathrm{Mn}$ segregation was eliminated were also prepared for comparison. The resultant microstructure was examined for compressive strains between 0.7 and 2.1 .

When the austenite grain size is 160 or $120 \mu \mathrm{m}$ prior to GRP, the ferrite grain size of the samples with the $\mathrm{Mn}$ segregation is smaller at the given strain than that of the samples from which the Mn segregation was eliminated. The $\mathrm{Mn}$ band formed by the heavy compression is thought to act as a barrier in the form of a relatively stable austenite against the ferrite growth.

Moreover, we found a unique equation to predict the transformed ferrite grain size in the samples with the Mn segregation. Namely, the ferrite grain size can be accounted for according to a parameter, ES (effective spacing): a mean spacing that considers both the pancake austenite grain boundary and the $\mathrm{Mn}$ band. We also suggest that the smaller $\mathrm{Mn}$ band spacing may make the ferrite structure finer even when the austenite grain size is large.
\end{abstract}

KEY WORDS: cast slab; low carbon steel; heavy deformation; TMCP; HDR; HCR; phase transformation; grain boundary; ferrite grain; austenite grain; grain size; Mn segregation.

\section{Introduction}

Ultra-fine grained ferrite structure has been pursued to improve strength and toughness simultaneously. Large plastic deformation in the so-called "unrecrystallized" austenitic regime and subsequent controlled cooling (hereafter mentioned as Grain Refinement Process: GRP) will generate ferrite grains that are smaller than $5 \mu \mathrm{m}$.

In the last decade, the rolling process that is directly-connected with continuous casting called the Hot Direct Rolling (HDR) process or the Hot Charge Rolling (HCR) process has advanced as an energy-saving manufacturing process of hot rolled steel products as shown in Fig. 1. ${ }^{1-4)}$ Although some have reported mechanical properties with sheets produced by the HDR or HCR process ${ }^{5,6}$ extensively, only a few have investigated the relationship between the process conditions and the ferrite grain structure.

In particular, the microstructure prior to GRP may have a significant influence on the evolution of the ferrite grain structure. In other words, it is very important to understand the kind of microstructure that is the most effective as the initial microstructure prior to GRP in the HDR or HCR process.

The microstructure prior to GRP depends on the precedent treatments and can be classified into four categories according to the austenite grain structure and the degree of micro-segregation as summarized in Table $\mathbf{1 .}$

Type 1 is the as-cast or the as-solidified microstructure. The morphology of austenite grains is mostly columnar with a grain size of several millimeters. The solidified structure remains, and the micro-segregation is dominant.

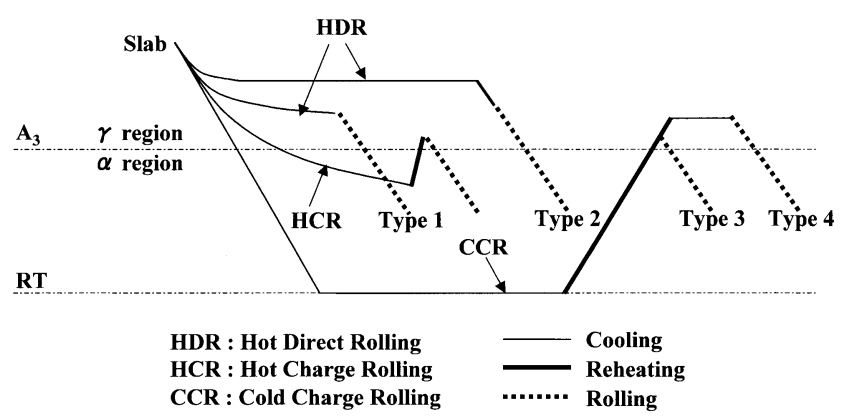

Fig. 1. Schematic schedule for manufacturing of hot rolled steel plates.

Table 1. Four kinds of microstructures.

\begin{tabular}{|c|c|c|}
\hline & Austenite grain size & Micro-segregation \\
\hline Type 1 & $\geqq 1 \mathrm{~mm}$ & Not eliminated \\
\hline Type 2 & $\geqq 1 \mathrm{~mm}$ & Eliminated \\
\hline Type 3 & $20 \sim 300 \mu \mathrm{m}$ & Not eliminated \\
\hline Type 4 & $20 \sim 300 \mu \mathrm{m}$ & Eliminated \\
\hline
\end{tabular}


Type 2 is the homogenized form of Type 1 without forging. The micro-segregation disappears by heating for several hours at an elevated temperature. The austenite grain size is large. This type is not always utilized practically but is important from a scientific viewpoint.

For Types 1 and 2 microstructures, the recrystallization process has been developed and essentially combined with GRP to obtain fine austenite grains. The addition of $\mathrm{Nb}$ and Ti has been adopted for this purpose especially for Type $1 .^{7-11)}$

Type 3 is the reheated form of Type 1 that is cooled once in the fully ferritic temperature regime. The micro-segregation remains but the austenite structure becomes equi-axed and smaller. The austenite grain size is between 20 and $300 \mu \mathrm{m}$.

Type 4 is somehow classical. First the solidified structure is destroyed by some deformation at an elevated temperature, then it is homogenized and normalized. Figure 2 illustrates the difference between Types 3 and 4 microstructures prior to GRP. Micro-segregation does not exist, and the austenite grain size is mostly as small as that of Type 3 . Torizuka et al. reported that the size of ferrite grains transformed from the heavily deformed austenite depends on the thickness of the compressed austenite grain for a $\mathrm{Si}-\mathrm{Mn}$ steel with a Type 4 microstructure. ${ }^{12,13)}$

For Types 3 and 4 microstructures, a fine austenite grain size can be easily obtained by austenitizing or reheating the steel for a relatively short period in a lower austenitic temperature. The micro-segregation is believed to decrease the toughness of the perpendicular direction of the rolled plate. ${ }^{14)}$ To eliminate the micro-segregation, forging and/or homogenization have been applied using Types 2 and 4 . However, for practical cases, such treatment is not always adequate to eliminate the micro-segregation with Types 1 and 3 .

It is easier to obtain fine austenite grains with Type 3 than with Type 1. Type 3 does not need the previous reduction of continuous casting slab (CC-slab) thickness, and it has more room for heavy reduction in the TMCP with a given slab thickness. Hence, in a practical meaning, the finer ferrite structure may be obtained more easily in Type 3 than in Type 1.

Therefore, in the present study, we have clarified how the fine ferrite structure can be produced for the Type $3 \mathrm{mi}-$ crostructure in the same way as that for Type 4 by comparing it to the Type 4 case for the low carbon Si-Mn steel.

The ferrite grain refinement through the $\gamma-\alpha$ transformation is discussed by the following three factors:

(1) Density of nucleation sites

(2) Nucleation rate

(3) Grain growth rate

The major difference between Types 3 and 4 is the existence of the micro-segregation. Thus, intensive attention should be given to how the micro-segregation influences these three controlling factors.

At a constant cooling rate, the density of the nucleation site is the main factor for determining the ferrite grain size as reported by Torizuka et al., since the austenite grain boundary acts as the preferential nucleation site in the heavy deformation condition. So far, there has not yet been any clarification on how the micro-segregation affects this
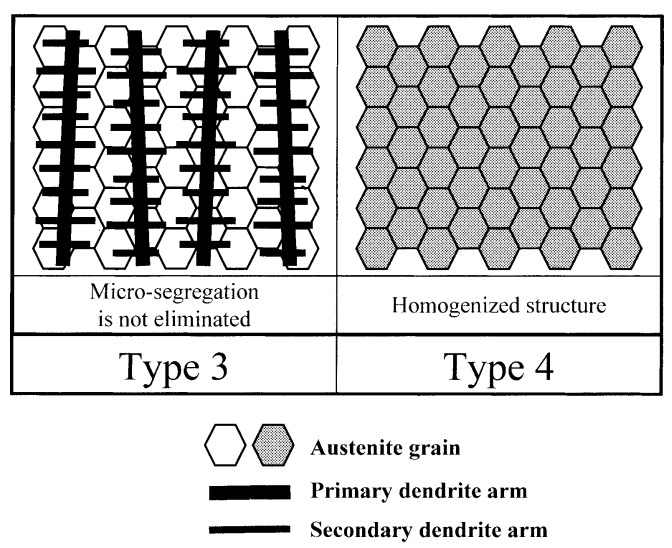

Fig. 2. Comparison of austenite grain structures for Types 3 and 4.

Table 2. Chemical compositions of the investigated steel (mass\%).

\begin{tabular}{|c|c|c|c|c|}
\hline $\mathrm{C}$ & $\mathrm{Si}$ & $\mathrm{Mn}$ & $\mathrm{P}$ & $\mathrm{S}$ \\
\hline 0.11 & 0.16 & 0.58 & 0.01 & 0.003 \\
\hline
\end{tabular}

factor.

The nucleation rate is also related to the degree of undercooling. The beginning temperature for phase transformation ( $=\mathrm{A}_{\mathrm{r} 3}$ point) may change by the concentration distribution of the micro-segregation. Ouchi et al. introduced the following equation concerning the $\mathrm{A}_{\mathrm{r} 3}$ point of the steel rolled by a $50 \%$ reduction or more in the unrecrystallized austenite region $^{15)}$ :

$$
\begin{gathered}
\mathrm{A}_{\mathrm{r} 3}\left({ }^{\circ} \mathrm{C}\right)=910-310 \mathrm{C}-80 \mathrm{Mn}+0.35(t-8) \ldots \ldots \ldots . .(1) \\
t: \text { thickness of plate }(\mathrm{mm})
\end{gathered}
$$

Thus, a highly segregated area has a large degree of under-cooling. Furthermore, the height or the profile of the Mn segregation may also affect the grain growth rate.

In the present study, the effect of heavy deformation of austenite on the grain size of the transformed ferrite has been clarified using a $100 \mathrm{~mm}$ thick CC-slab of the low carbon $\mathrm{Si}-\mathrm{Mn}$ steel with special attention on the Type $3 \mathrm{mi}-$ crostructure with the Mn micro-segregation.

\section{Experimental Procedures}

\subsection{Sample Preparation}

The chemical compositions of the investigated steel are listed in Table 2. The steel is a SS400 grade. A continuous cast slab made in a laboratory-scale was prepared for the present study. The details of the casting are reported in the literature by Yoshida et al. ${ }^{16)}$ and also mentioned in Table 3 with other preparations for GRP samples. The average spacing of the primary dendrite arms was $318 \mu \mathrm{m}$ and the average spacing of the secondary dendrite arms was $137 \mu \mathrm{m} .{ }^{16)}$

Using this slab, each specimen with or without the elimination of micro-segregation was prepared. The former was cut directly from a quarter thickness of the slab for the Type 3 microstructure, and the latter was rolled to a plate by $70 \%$ in nominal reduction ratio and reheated for $86.4 \mathrm{ks}$ at $1623 \mathrm{~K}$ to eliminate the Mn micro-segregation for the Type 
Table 3. Conditions of the pre-treatment and the Grain Refinement Process

\begin{tabular}{|c|c|c|c|c|}
\hline & \multicolumn{3}{|c|}{ Pre-treatment Process } & \multirow{2}{*}{$\frac{\text { Grain Refinement Process }}{\text { Compression/Controlled Cooling }}$} \\
\hline & $\begin{array}{l}\text { Continuous } \\
\text { Casting }\end{array}$ & Homogenization & Austenitization & \\
\hline Type 3 & \multirow[b]{2}{*}{$\begin{array}{l}\text { Melt: } 2.5 \text { ton } \\
\text { Casting Velocity: } \\
0.8-1.0 \mathrm{~m} / \mathrm{min} \\
\text { Slab Size: } \\
100 \mathrm{mmT} \\
800 \mathrm{mmW} \\
3000 \mathrm{mmL}\end{array}$} & & \multirow{2}{*}{$\begin{array}{l}\text { Heating Rate: } \\
5 \mathrm{~K} / \mathrm{s} \\
\text { Reheating } \\
\text { Temperature: } \\
\text { 1) } 1473 \mathrm{~K} \text {, and } \\
\text { 2) } 1223 \mathrm{~K} \\
\text { Holding Time: } \\
60 \mathrm{~s}\end{array}$} & \multirow{2}{*}{$\begin{array}{l}\text { Cooling Rate: } \\
10 \mathrm{~K} / \mathrm{s} \\
\text { Compression: } \\
\text { Temperature: } 1093 \mathrm{~K} \\
\text { Reduction Rate: } 30 \%, 50 \%, 75 \% \\
\text { Strain rate: } 10 / \mathrm{s} \\
\text { Controlled Cooling: } \\
10 \mathrm{~K} / \mathrm{s}\end{array}$} \\
\hline Type 4 & & $\begin{array}{l}\text { 1)Rolling } \\
\text { Heating: } \\
1273 \mathrm{~K}, 40 \mathrm{~min} \\
\text { Start: } 1273 \mathrm{~K} \\
\text { Finish: } 1093 \mathrm{~K} \\
\text { Reduction rate: } 70 \% \\
\text { 2)Reheating } \\
\text { 1623 K, } 86.4 \mathrm{ks}\end{array}$ & & \\
\hline
\end{tabular}

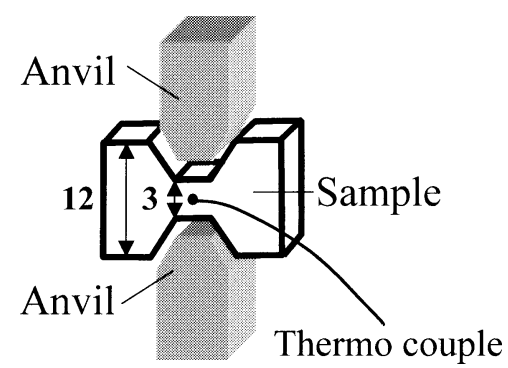

Fig. 3. Schematics of the hot compression test.

4 microstructure.

\subsection{Grain Refinement Process (GRP)}

GRP samples with a thickness of $12 \mathrm{~mm}$, a length of 16 $\mathrm{mm}$, and a width of $15 \mathrm{~mm}$ were machined from the specimens mentioned above. Prior to GRP, two kinds of reheating were employed to change the austenite grain size: holding for $60 \mathrm{~s}$ at 1223 and $1473 \mathrm{~K}$, respectively.

Figure 3 describes the hot compression test as a simulation of GRP. A sample sandwiched between a couple of anvils is heated directly by electric resistance heating and then compressed with a servo-hydraulic machine to a final thickness at a given temperature. The axis of compression is perpendicular to the direction of the secondary dendrite arms and parallel to the direction of the primary dendrite arms.

In the present study, compression with a nominal reduction ratio of 30,50 and $75 \%$ at a strain rate of $10 / \mathrm{s}$ was applied at $1093 \mathrm{~K}$, followed by controlled cooling at $10 \mathrm{~K} / \mathrm{s}$. The $A_{r 3}$ point of the Type 4 samples with a prior austenite grain size of $20 \mu \mathrm{m}$ was determined to be $1073 \mathrm{~K}$ at a cooling rate of $10 \mathrm{~K} / \mathrm{s}$ from the thermal expansion test results. Hence the deformation temperature of $1093 \mathrm{~K}$ was chosen as the temperature in the 'unrecrystallized austenite regime'. The compressive strain ranges from zero at the surface of the sample to a maximum value of 4.6 at the center of the sample with a nominal reduction ratio of $75 \%$ (Fig. 4). The subsequent structure by a wide range of strains can be examined in a sample using this method. However, in the present study, the strain range up to 2.1, which corresponds to the maximum in the nominal reduction ratio of $50 \%$, was adopted for the following analysis on the ferrite grain size since the useful effect of the practical strain or a strain that is not heavy should be explored

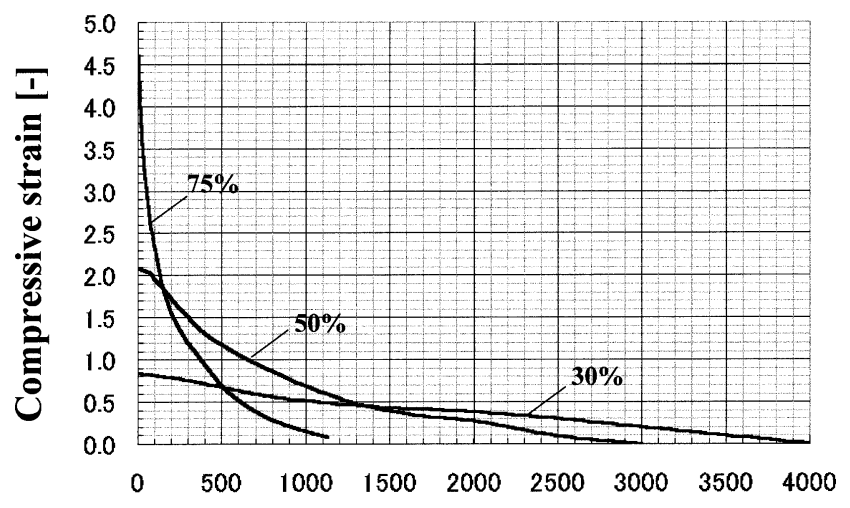

Distance from surface of sample $[\mu \mathrm{m}]$

Fig. 4. Calculated compressive strain distribution in a sample.

first with high reliability.

\subsection{Microstructural Characterization}

\subsubsection{Microstructure}

Microstructural observation was carried out on a section cut through the center of the GRP sample parallel to the compression axis. Etchants for metallography were $3 \mathrm{vol} \%$ picric acid for observing the prior-austenite structure and 3 vol\% nitric acid for the ferrite grains. The average ferrite grain size $(\bar{d})$ was determined by the equation of $\bar{d}=1.128 d$. The $d$ corresponds to the average intercept length at each strain and was measured by Heyn's method. ${ }^{17)}$

\subsubsection{Segregation}

The analysis of the Mn segregation was carried out by EPMA (Electron Probe Micro Analysis). Each of the sample sections for analysis was identical to that in the microstructural observation. The EPMA was set at $15 \mathrm{kV}-$ $1 \mathrm{~mA}$. The pixel size was $5 \mu \mathrm{m}$ in square for the as-cast samples and $1 \mu \mathrm{m}$ in square for the GRP samples. The number of pixel data was 250000 per section.

\section{Results}

\subsection{Microstructural Characteristics Prior to Grain Refinement Process}

\subsubsection{Austenite Grain Size}

Figure 5 shows the prior-austenite grain structures after 


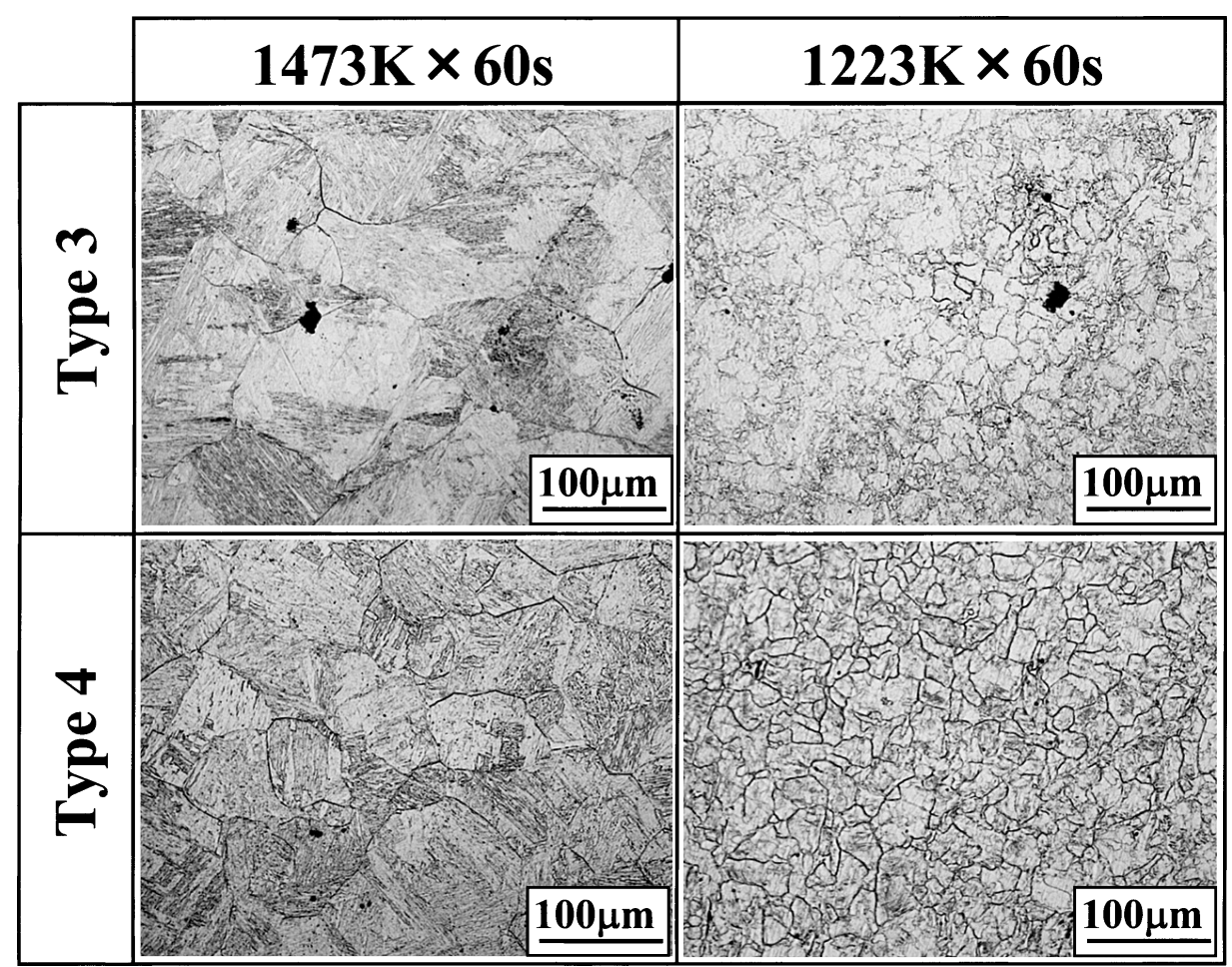

Fig. 5. Comparison of austenite grain structures ( 3 vol $\%$ Picral etched).

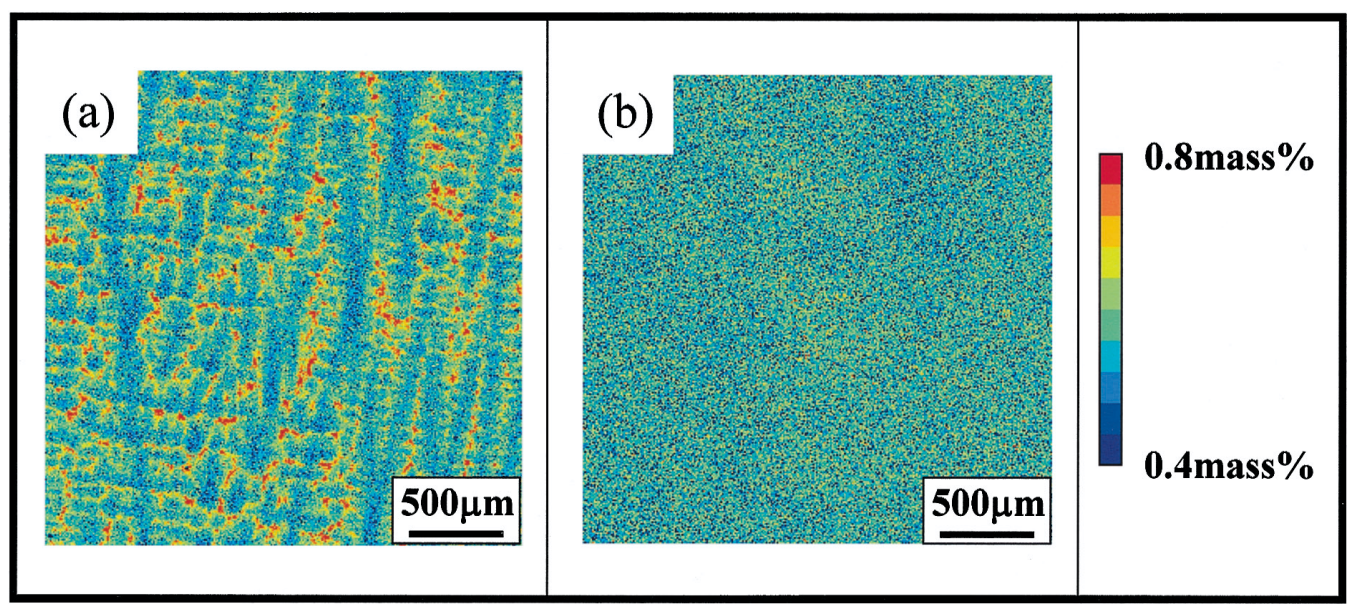

Fig. 6. Comparison of the distribution of Mn segregation prior to the grain refinement process. (a): Type 3, (b): Type 4 .

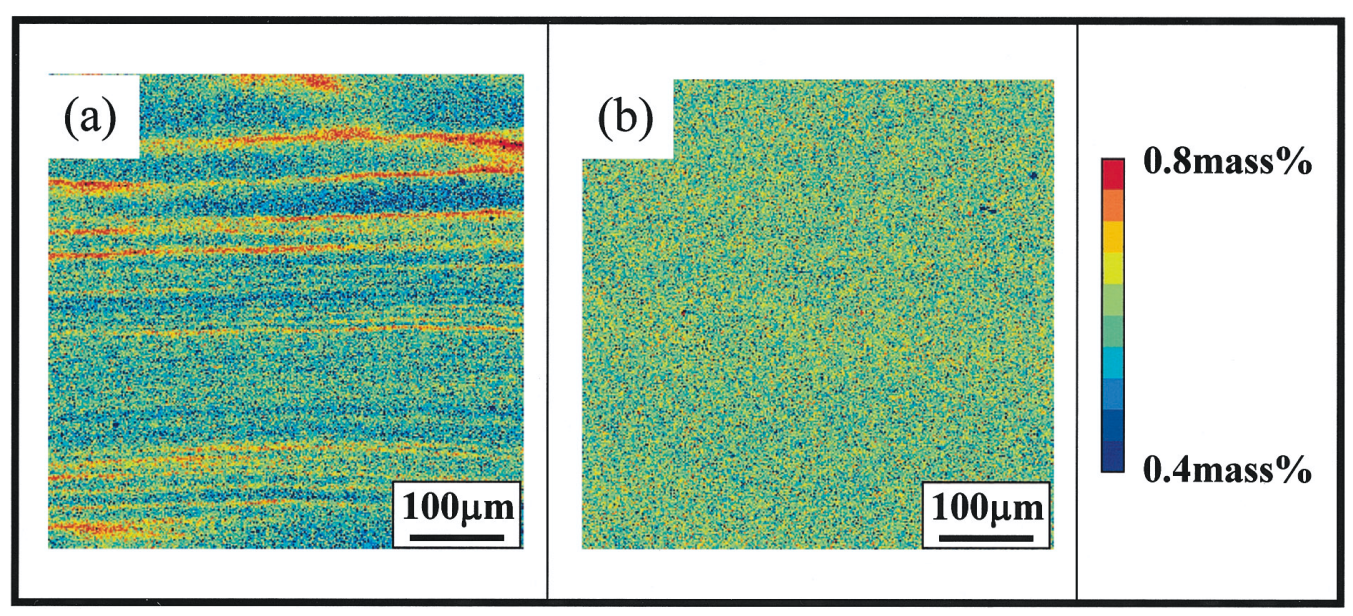

Fig. 7. Comparison of the distribution of Mn segregation in the compressed samples. (a): Type 3, (b): Type 4. 
heating at 1223 and $1473 \mathrm{~K}$. In the samples heated at $1223 \mathrm{~K}$, the mean austenite grain size is $20 \mu \mathrm{m}$ for both Types 3 and 4 microstructures. In the samples heated at $1473 \mathrm{~K}$, the grain size is $160 \mu \mathrm{m}$ for Type 3 and $120 \mu \mathrm{m}$ for Type 4.

\subsubsection{Mn Segregation}

EPMA results demonstrates that Type 3 samples have the dendrite structure and the Mn segregation with a high concentration between the dendrite arms (Fig. 6(a)). The Mn concentration ranged from 0.4 to $0.8 \%$ with the lowest concentration in the dendrite arms and the highest concentration between the dendrite arms. On the other hand, the Mn segregation disappeared in Type 4 samples (Fig. 6(b)). In Type 4 samples, the Mn concentration disperses around the average of 0.58 mass $\%$ with a good distribution of $\mathrm{Mn}$ in the present condition.

\subsubsection{Change of Mn Segregation Morphology by Com- pression}

Figure 7 shows the Mn concentration maps by EPMA for Types 3 and 4 samples after the compression. It is clear that the Mn segregation in Type 3 samples does not disappear through the heating and compression. Here we define the term 'Mn band' as the elongated and Mn concentrated band. By observing the details, we can recognize that the Mn band spacing narrows with an increase in the compressive strain.

The change of the Mn band spacing for Type 3 samples in Fig. 4 is plotted against the compressive strain in Fig. 8. The error bars indicate the strain at both ends of the $\mathrm{Mn}$ band width. The Mn band was not detected in the highly compressed region with strains larger than 2.8 , partly because the probe diameter of EPMA was of $1 \mu \mathrm{m}$ order.

Pearlite is a transformed structure from the austenite that remains after the ferrite transformation. When $\mathrm{Mn}$ as an austenite stabilizer is concentrated in the form of a band in Type 3 samples, such a region is believed to be the last one to remain in the austenite regime. Hence the pearlite band can be used as a trace of the Mn band in the largely compressed samples. As a matter of fact, the pearlite bands are observed in the largely compressed Type 3 samples and will be introduced later in Fig. 9. On the other hand, such a pearlite band is not seen for Type 4 samples where the Mn is distributed homogeneously. In Fig. 8, the pearlite band spacing is also plotted in a similar manner to the Mn band.

Assuming that the Mn band originally corresponds to the Mn concentrated area between the secondary dendrite arms as seen in Fig. 6, the Mn band spacing, $L$, is believed to reflect the compressed secondary dendrite arm spacing:

$$
L=L_{0} \cdot \exp (-\varepsilon)
$$

$L$ : $\quad$ Mn band spacing (in $\mu \mathrm{m}$ )

$L_{0}$ : Secondary dendrite arm spacing $(=137 \mu \mathrm{m})$

$\varepsilon$ : Compressive strain

The straight line drawn in Fig. 8 is the one calculated by Eq. (2), and accounts for the relationship between the compressive strain and the Mn band spacing. Hence, we can notice that the secondary dendrite arms are compressed according to Eq. (2), and the spacing of the Mn and/or the pearlite band are also similar.

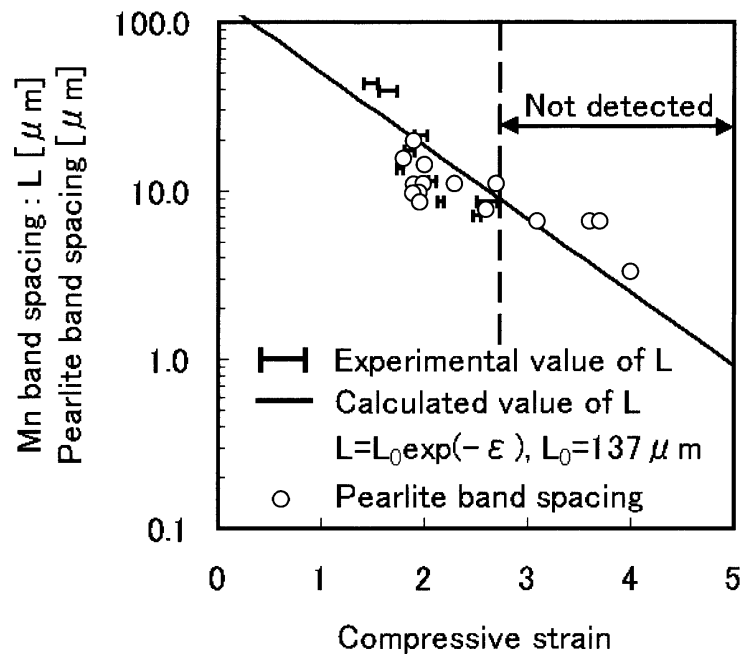

Fig. 8. Change of Mn band and pearlite band spacing by compressive strain.

\subsection{Ferrite Grain Structure after GRP}

\subsubsection{Ferrite Structure}

Figure 9 shows the ferrite grain structures by GRP. The compression direction is vertical and the elongating direction horizontal in each microphotograph.

When the austenite grain size is $20 \mu \mathrm{m}$ (Fig. 9(a)), the ferrite grains for Type 4 samples are polygonal and uniformly fine. On the other hand, when the austenite grain sizes are 160 and $120 \mu \mathrm{m}$ (Fig. 9(b)), the ferrite grain size clearly depends on the strain. The smaller size is given by the larger strain. A small volume fraction of pearlites are also observed. In Type 4 samples the pearlites are dispersed uniformly, but in Type 3 samples they form arrays when the strain is 2.1 as mentioned above. When the compressive strain is 0.8 , the Mn band spacing is larger than $50 \mu \mathrm{m}$ from Fig. 7. Hence the partitioning process may be active inside the austenite grain and bring about a uniform distribution of pearlites that can be seen in Fig. 9(b).

\subsubsection{Ferrite Grain Size}

Figure 10 shows the change of the mean ferrite grain size by the compressive strain. When the austenite grain size is $20 \mu \mathrm{m}$, the ferrite grain size for Type 4 samples does not depend much on the strain but decreases slightly with increasing compressive strain. A ferrite grain size of $5 \mu \mathrm{m}$ can be obtained only by a heavy strain of at least 2 .

When the austenite grain size is 160 or $120 \mu \mathrm{m}$, a larger ferrite grain size is derived than when the austenite grain size is $20 \mu \mathrm{m}$. Furthermore, the ferrite grain size of Type 3 samples with a larger austenite grain size is smaller than that of Type 4 samples at a given strain.

According to the analysis by Torizuka et al., the ferrite grain sizes in Fig. 9 can be rearranged against the pancake austenite grain thickness (geometrical factor: $\mathrm{TH}_{\gamma}$ ) in Fig. 11 $^{12,13)}$ : where

$$
\mathrm{TH}_{\gamma}=d_{0} \cdot \exp (-\varepsilon)
$$

$d_{0}$ : Initial austenite grain thickness $(\mu \mathrm{m})$

$\varepsilon$ : Compressive strain

The ferrite grain sizes with different initial austenite grain sizes are expressed well as a function of $\mathrm{TH}_{\gamma}$ for each of the Types 3 and 4 samples. $\mathrm{TH}_{\gamma}$ is a useful measure of 


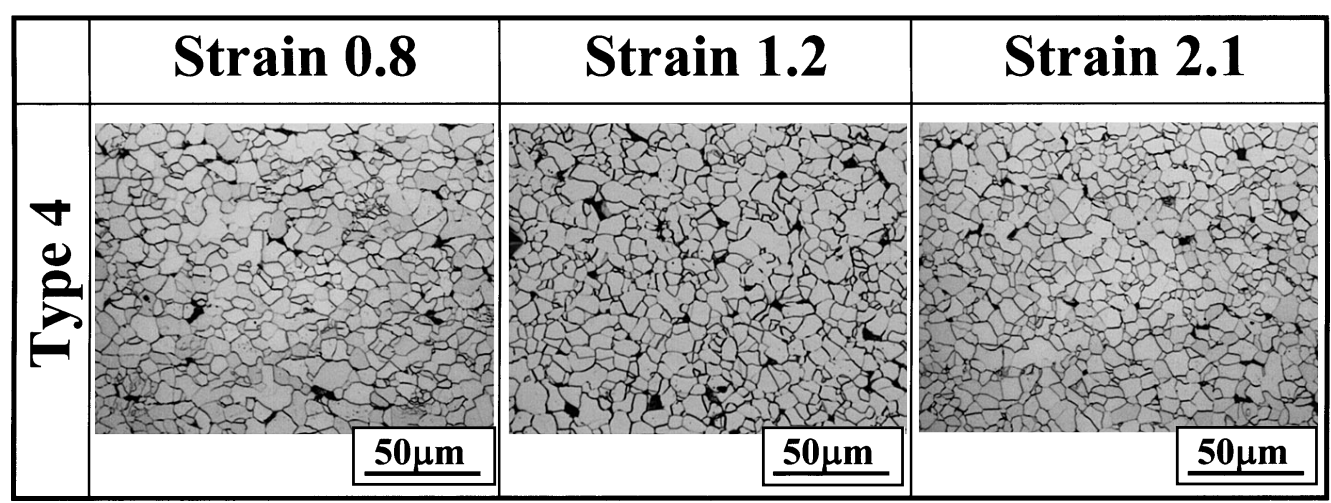

Fig. 9(a). Change of ferrite grain structures by compressive strain, in Type 4 samples with a prior-austenite grain size of $20 \mu \mathrm{m}$.

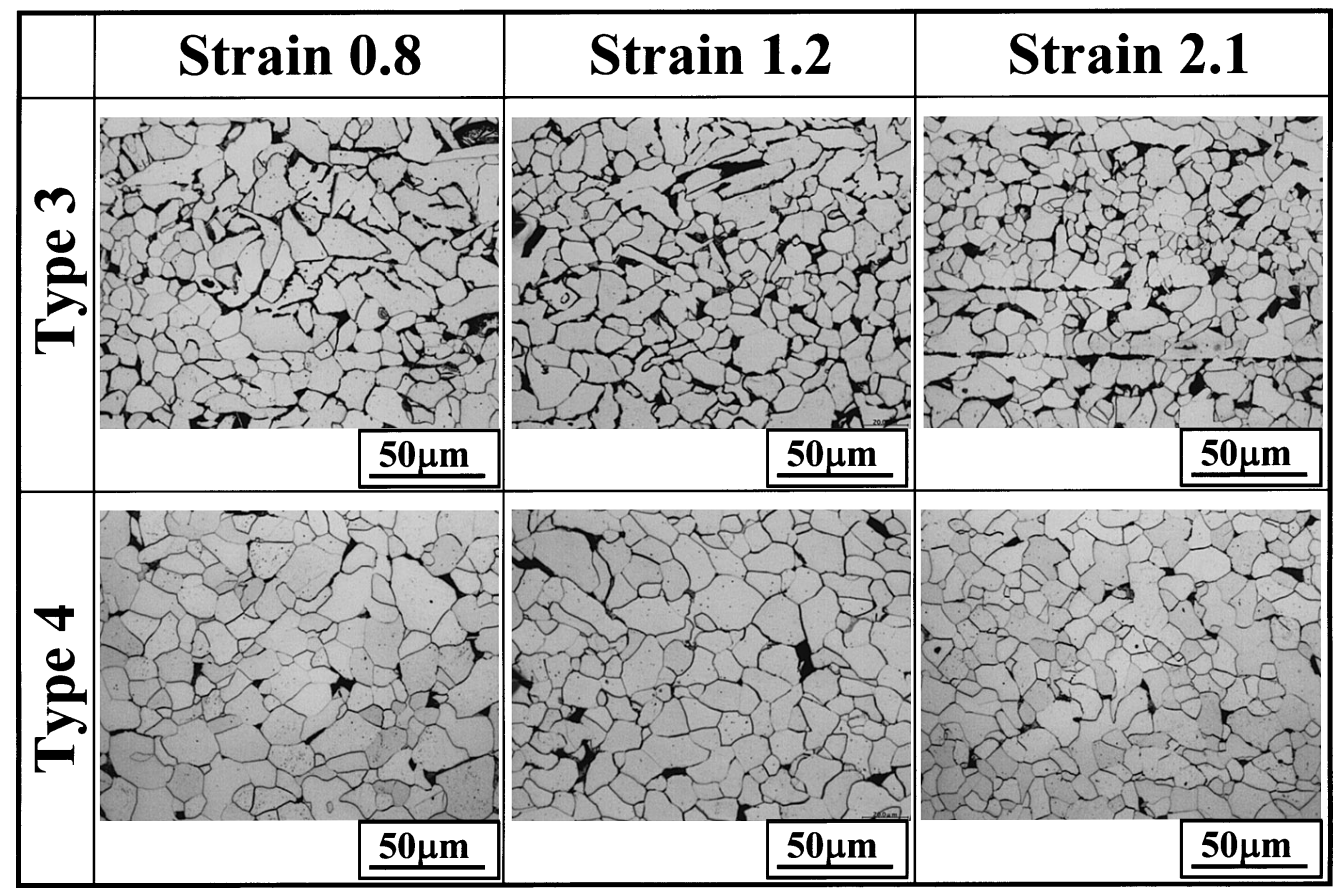

Fig. 9(b). Change of ferrite grain structures by compressive strain, in the samples with prior-austenite grain sizes of $160 \mu \mathrm{m}$ (Type 3) and $120 \mu \mathrm{m}$ (Type 4).

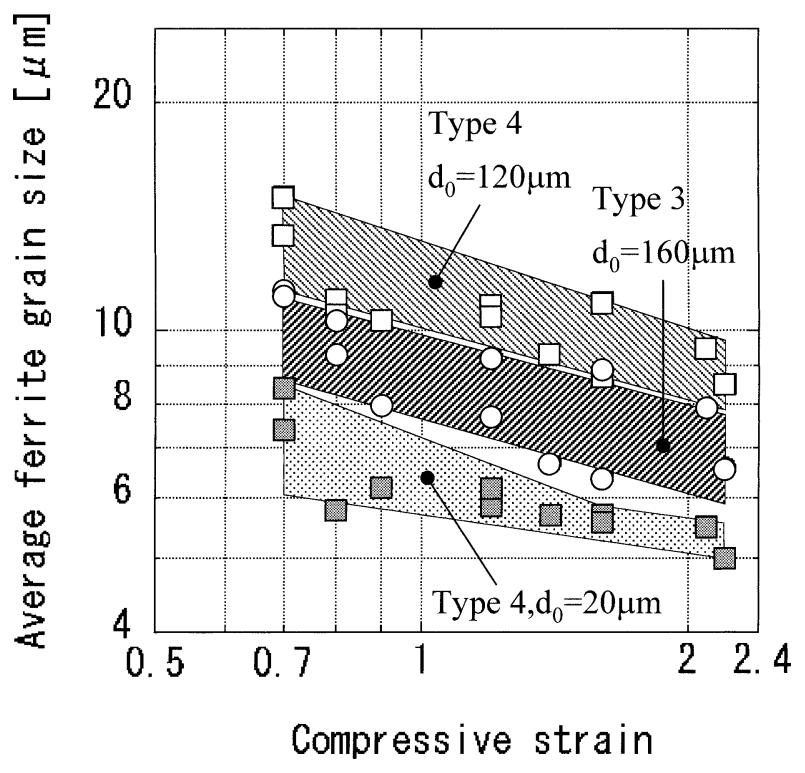

Fig. 10. Change of ferrite grain size by compressive strain.

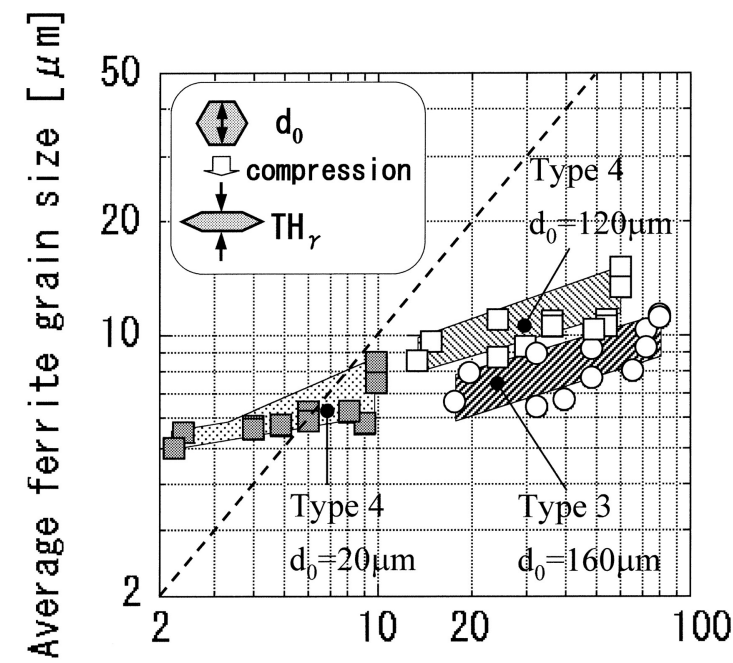

Pancake austenite grain thickness: $\mathrm{TH}_{\gamma}[\mu \mathrm{m}]$ $\mathrm{TH}_{\gamma}=\mathrm{d}_{0} * \exp (-\varepsilon)$

Fig. 11. Relationship between ferrite grain size and pancake austenite grain thickness: $\mathrm{TH}_{\gamma}[\mu \mathrm{m}]$. 

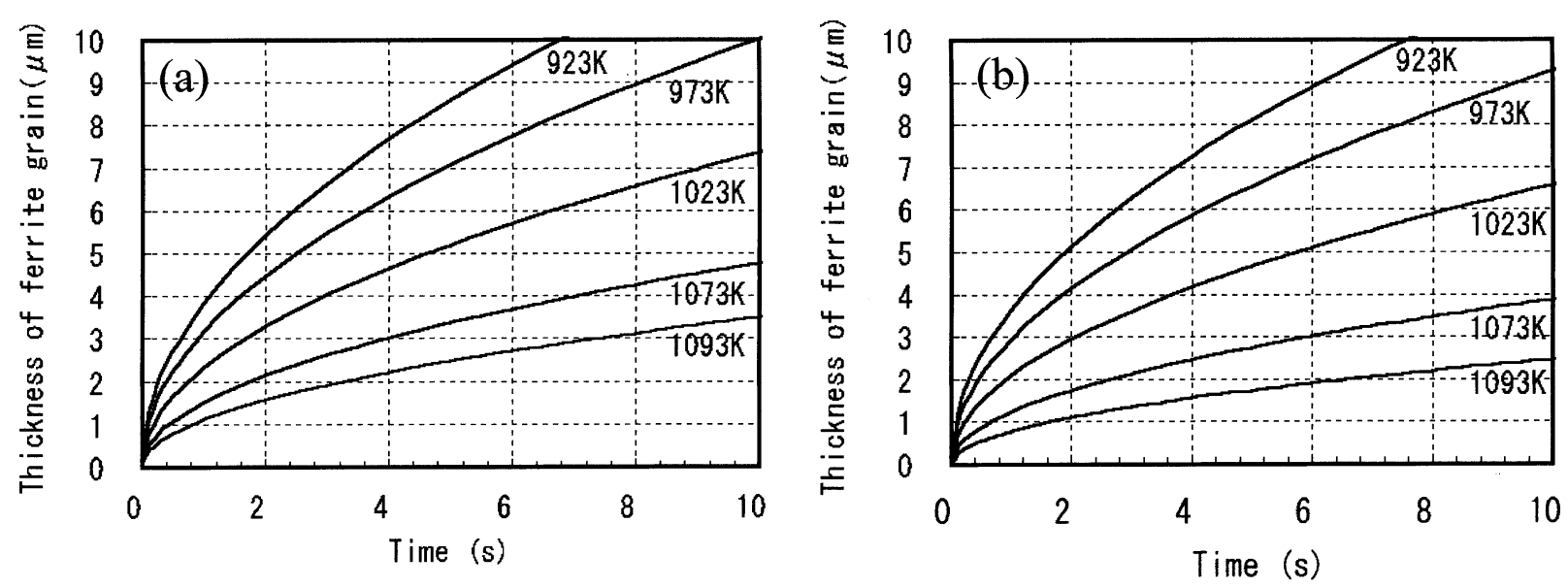

Fig. 12. Calculated ferrite grain growth in holding at given temperatures. (a): $\mathrm{Mn}=0.4 \mathrm{mass} \%$, (b): $\mathrm{Mn}=0.8 \mathrm{mass} \%$.

the density of the nucleation site in the ferrite transformation from the heavily deformed austenite. Figure 11 confirms the significance of their approach. When $\mathrm{TH}_{\gamma}$ is larger than approximately $2 \mu \mathrm{m}$, the ferrite grain size becomes smaller with decreasing $\mathrm{TH}_{\gamma}$.

Note that the ferrite grain size of Type 3 samples is clearly smaller than that of Type 4 samples at a given $\mathrm{TH}_{\gamma}$ when $\mathrm{TH}_{\gamma}$ is larger than $15 \mu \mathrm{m}$. This indicates the possibility of a higher density of the nucleation site in Type 3 samples than in Type 4 samples. However, Type 3 samples have the distinct $\mathrm{Mn}$ segregation. The high concentration of Mn may affect the nucleation and the growth of ferrite. The mechanism that has the most influence on the difference in Fig. 11 will be discussed in the next chapter.

\section{Discussion}

\subsection{Influence of Mn Segregation on Nucleation and Growth of Ferrite}

In Fig. 6, the width of the Mn segregation band with no strain was about a tenth of the secondary dendrite arm spacing $(137 \mu \mathrm{m})$. The $\mathrm{Mn}$ concentration is $0.8 \%$ at the peak and $0.4 \%$ at the bottom. According to Eq. (1), the $A_{r 3}$ point is $30 \mathrm{~K}$ lower at the peak than at the bottom. Hence, by assuming the uniform nucleation of ferrite, the ferrite may become nucleated at the center of the bottom and start to grow. Due to the cooling rate of $10 \mathrm{~K} / \mathrm{s}$, the temperature at the $\mathrm{Mn}$ peaks reaches its $\mathrm{A}_{\mathrm{r} 3}$ point $3 \mathrm{~s}$ after the start of nucleation at the bottom.

Figure 12 shows the prediction of the growth rate of the interface between the austenite and ferrite in holding at given temperatures for the 0.4 and $0.8 \% \mathrm{Mn}$ compositions. ${ }^{16)}$ The present prediction says that although the difference is not large, a lower growth rate is expected for the $0.8 \% \mathrm{Mn}$ than for the $0.4 \% \mathrm{Mn}$. When we assume that the transformation starts after the compression below $1093 \mathrm{~K}$ and finishes above $973 \mathrm{~K}$, the ferrite size may reach a value between 2 and $5 \mu \mathrm{m}$ in $3 \mathrm{~s}$. The lower the transformation temperature range, the more the growth. Hence the 'free growth' of the ferrite is believed to be a minimum of $2 \mu \mathrm{m}$ and a maximum of $5 \mu \mathrm{m}$ at the bottom of the Mn concentration for the Type 3 samples.

Thus, other ferrites that are the same size as the initial one may be formed in the bottom area if their width is larg- er than $5 \mu \mathrm{m}$, and finer ferrites may be formed in the Mn band if the band has enough width. However the mean size of ferrites grains will not be influenced much by the finer grains nucleated in the $\mathrm{Mn}$ band, since the effect has to be an order of $10 \%$ because the width of the $\mathrm{Mn}$ band is a tenth of the bottom width.

The Mn band may remain in the austenite regime due to the 'local equilibrium' at the end of the transformation in the bottom width. This suggests that in the heavily compressed condition, the Mn band in the austenite regime may act as a barrier against the ferrite growth and finally be transformed into pearlite. No additional ferrite influences the mean size of ferrites.

The under-cooling also affects the nucleation rate. The $\mathrm{A}_{\mathrm{r} 3}$ point at the bottom of the Mn segregation for Type 3 samples is estimated to be about $15 \mathrm{~K}$ higher than that of the bulk for Type 4 samples. However, this requires a lower nucleation rate for Type 3 samples than for Type 4 samples when they are subjected to a similar temperature history. Since finer ferrites were obtained for Type 3 samples, the possible difference in the nucleation rate due to the Mn segregation is also not plausible for the present result.

\subsection{Barriers against Ferrite Growth}

The grain boundary is the preferential nucleation site for ferrite in the heavily deformed austenite. We consider that each potential nucleation site is highly activated and that simultaneous nucleation is very much probable in the heavily deformed austenite. Furthermore, only the first nucleated grains survive by killing the neighboring potential sites under the condition that the growth rate is higher than $1 \mu \mathrm{m} / \mathrm{s}$. Once transformed, the ferrites can act as barriers against the growth of each other, since the growth here means the transformation of austenite to ferrite.

Under such circumstances with highly dense nucleation sites and a rapid growth rate, we can discuss the possibility of a refinement effect by the growth barrier density or the suppression of 'free growth'. In Type 4 samples, the pancake austenite boundary acts as a growth barrier as well as a nucleation site. In Type 3 samples, the Mn band may also originally act as a growth barrier.

Figure 13 illustrates this idea, which implies the dividing effect of a pancake austenite by the Mn bands. Such division might initiate a delayed nucleation in the remaining 


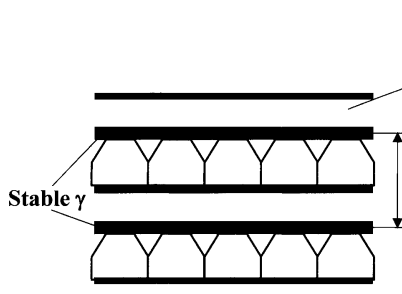

(a)

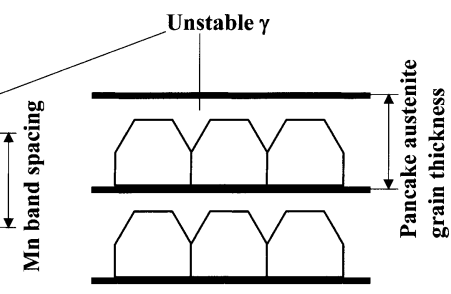

(b)

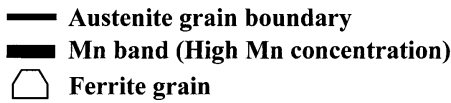

Fig. 13. Evolution of fine ferrite structure of Type 3 sample compared with Type 4 samples. (a): Type 3, (b): Type 4

austenite regime that is blocked against the ferrite 'free growth' by the Mn band. In this sense, the Mn band can be regarded as an additional nucleation site. In other words, the ferrite is nucleated in the region between the Mn bands even if no austenite grain boundary exists within it.

\subsection{Effective Parameter to Determine Ferrite Grain Size}

The Mn band spacing may also control the ferrite grain size for Type 3 samples. Hence we propose an effective spacing parameter, ES, by modifying the geometrical factor, $\mathrm{TH}_{\gamma}$, defined by Eq. (3), in the following way:

$$
A=\frac{1}{\mathrm{TH}_{\gamma}}+\frac{1}{L}
$$

$A$ : Total number of austenite grains and $\mathrm{Mn}$ bands per unit length

$L:$ Mn band spacing (in $\mu \mathrm{m}$ ) defined by Eq. (2)

$$
\mathrm{ES}=\frac{1}{A}=\frac{L \cdot \mathrm{TH}_{\gamma}}{L+\mathrm{TH}_{\gamma}}=\frac{L_{0} \cdot d_{0}}{L_{0}+d_{0}} \exp (-\varepsilon)
$$

\section{ES: Effective spacing (in $\mu \mathrm{m}$ )}

Figure 14 rearranges the data in Fig. 11 by replacing $\mathrm{TH}_{\gamma}$ by ES. The two bands in Fig. 11 meet into a single band successfully, which postulates the validity of our idea that the Mn band together with the austenite grain boundary acts as a growth barrier or a nucleation site in determining the ferrite grain size formed from the largely compressed austenite. We can eventually conclude that the Mn segregation is beneficial for obtaining a finer ferrite grain size through the GRP. In addition, we can design the ferrite grain size quantitatively by controlling the secondary dendrite arm spacing, the initial austenite grain size, the compressive strain, and the deformation temperature in the GRP in the present study for both Types 3 and 4 samples.

Figure 15 demonstrates the relationship between ES and $L_{0}$, the secondary dendrite arm spacing taking $d_{0}$, the initial austenite grain size, as a parameter when the compressive strain is 0 . Even if $d_{0}$ is quite large, ES becomes very small with a small $L_{0}$. On the other hand, when $d_{0}$ is as small as $20 \mu \mathrm{m}$, ES is almost independent of $L_{0}$. It has been said that the coarse austenite structure prevents the refinement of the ferrite grains in the HDR process or the HCR process. However, the present paper suggests that the smaller secondary dendrite arm spacing may make the ferrite structure

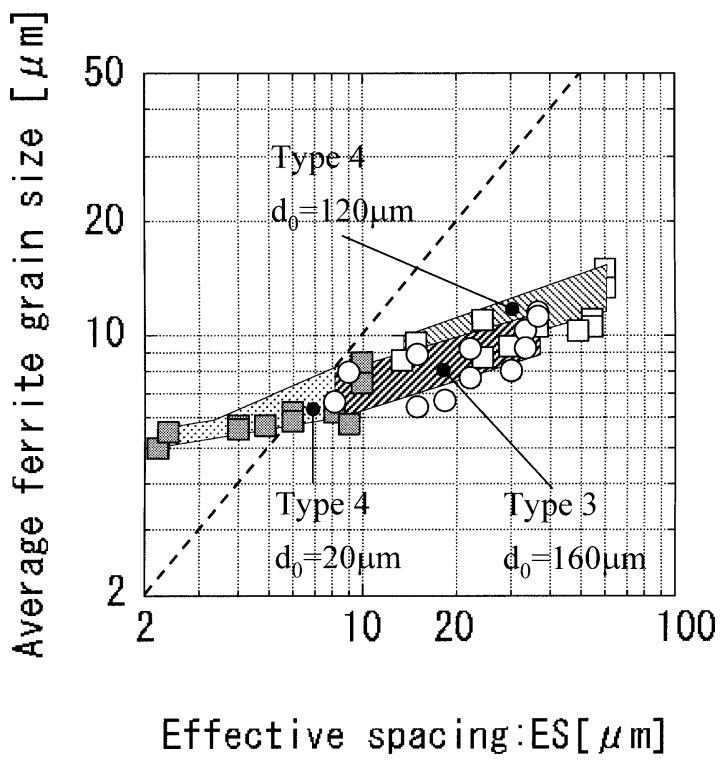

Fig. 14. Relationship between ferrite grain size and effective spacing.

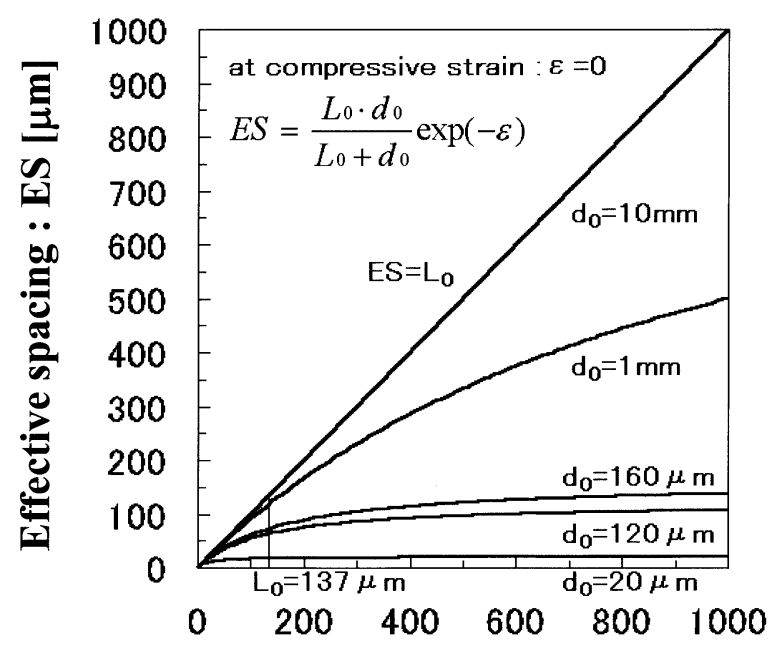

Secondary dendrite arm spacing : $\mathrm{L}[\mu \mathrm{m}]$

Fig. 15. Relationship between effective spacing and secondary dendrite arm spacing with various initial austenite grain sizes.

even finer in the heavy compression even when the austenite grain size is quite large. The secondary dendrite arm spacing can be refined by a higher cooling rate in continuous casting. ${ }^{18)}$

\section{Conclusions}

Using a $100 \mathrm{~mm}$ thick continuously cast slab with a chemical composition of $0.10 \mathrm{C}-0.16 \mathrm{Si}-0.58 \mathrm{Mn}-0.01 \mathrm{P}-$ $0.003 \mathrm{~S}$ (mass\%), we clarified the effect of the manganese micro-segregation that formed during solidification on the size of the ferrite grains that were transformed from the heavily deformed and unrecrystallized austenite. Specimens were cut from the cast slab and subjected to a compressive deformation perpendicular to the secondary dendrite arms with parallel alignment. The ferrite microstructure obtained was examined for compressive strains between 0.7 and 2.1. 
Specimens that were rolled by $70 \%$ in nominal reduction ratio and reheated for $86.4 \mathrm{ks}$ at $1623 \mathrm{~K}$ to eliminate the Mn micro-segregation were also prepared for comparison.

(1) A high Mn concentration of 0.8 mass $\%$ existed between the secondary dendrite arms. The highest Mn concentration had an initial spacing $\left(L_{0}\right)$ of $137 \mu \mathrm{m}$. The spacing narrowed with an increase in compressive strain $(\varepsilon)$ following the eq. $L=L_{0} \cdot \exp (-\varepsilon)$, and the Mn concentration became a band-like form ("Mn band"). The pearlite bands were also observed in the largely compressed samples, and the pearlite band spacing was essentially the same as the Mn band spacing.

(2) The ferrite grain size decreased with an increase in compressive strain in the unrecrystallized austenitic regime. Interestingly, the ferrite grain size for the samples with the Mn segregation (the initial austenite grain size of $160 \mu \mathrm{m}$ ) was smaller than that for the samples in which the Mn segregation was eliminated (the initial austenite grain size of $120 \mu \mathrm{m})$.

(3) Supposing that the Mn band has the same effect as the austenite grain boundary, the ferrite grain size can be expressed in a single band relationship according to a parameter, ES (effective spacing) without considering the initial austenite grain size or the existence of the Mn segregation. $\mathrm{ES}=L \cdot \mathrm{TH}_{\gamma} /\left(L+\mathrm{TH}_{\gamma}\right)$, where $\mathrm{TH}_{\gamma}$ is the austenite grain thickness, and $L$ is the Mn band spacing.

(4) The Mn band formed by the heavy compression is thought to act as a barrier in the form of a relatively stable austenite against the ferrite growth and subsequently induces an increase in the ferrite nucleation.

\section{Acknowledgments}

The authors would like to thank Dr. T. Inoue and Mr. N. Yoshida at NIMS for the helpful discussions and Ms. T. Nozawa and Ms. E. Tsuchiya for their assistance in observing the microstructures of the samples.

\section{REFERENCES}

1) K. Kawakami: Tetsu-to-Hagané, 74 (1988), 1203.

2) K. Kato: Tetsu-to-Hagané, 74 (1988), 1199.

3) K. Kawakami: Trans. Iron Steel Inst. Jpn., 27 (1987), 592.

4) I. Tamura: Trans Iron Steel Inst. Jpn., 27 (1987), 763.

5) P. C. Zambrano, M. P. Guerrero, R. Colas and L. A. Leduc: Mater. Charact., 47 (2001), 275

6) M. Suzuki, C. H. Yu, H. Shibata and T. Emi: ISIJ Int., 37 (1997), 862.

7) J. S. Park, M. Ajmal and R. Priestner: ISIJ Int., 40 (2000), 380.

8) A. I. Fernandez, P. Uranga, B. Lopez and J. M. Rodriguez: ISIJ Int., 40 (2000), 893.

9) A. Yoshie, T Fujita, M Fujioka, K.Okamoto, H. Morikawa and H Mabuchi: ISIJ Int., 36 (1996), 444.

10) A. Yoshie, T Fujita, M Fujioka, K. Okamoto, H. Morikawa and H Mabuchi: ISIJ Int., 36 (1996), 474.

11) Y. Kamada, T. Hashimoto and S. Watanabe: ISIJ Int., 30 (1990), 241.

12) S. Torizuka and K. Nagai: Tetsu-to-Hagané, 88 (2002), 42.

13) S. Torizuka, O. Umezawa, K. Tsuzaki and K. Nagai: Mater. Sci. Forum, 284-2 (1998), 225.

14) M. Nagumo, N. Okumura and T. Inoue: Seitetsu Kenkyu, 309 (1982), 140 .

15) C. Ouchi, T. Sampei and I. Kozasu: Trans. Iron Steel Inst. Jpn., 22 (1982), 214

16) N. Yoshida, O. Umezawa and K. Nagai: CAMP-ISIJ, 14 (2001), 599

17) M. Umemoto and I. Tamura: Jpn. Soc. Heat Treat., 24 (1984), 334.

18) H. Fuji, T. Ohashi, T. Ono and K. Asano: Nippon Steel Tech. Rep., 13 (1979), 48. 